\title{
A Bast-like valve in the pigeon?
}

\author{
Rutger Hofman $\cdot$ J. M. Segenhout $\cdot$ H. P. Wit
}

Received: 30 July 2008 / Accepted: 18 February 2009 / Published online: 6 March 2009

(C) The Author(s) 2009. This article is published with open access at Springerlink.com

\begin{abstract}
The first description of the presence of a utriculo-endolymphatic valve in human fetuses was given by Bast in 1928. Since then this valve-like structure is called Bast's valve. Its exact function has not yet been established. The general opinion is that it has a protective function by having the possibility to separate the superior endolymphatic compartments of the labyrinth from the inferior compartment. Phylogenetically seen birds are the first vertebrates with a cochlear duct and a distinct inferior and superior part of the labyrinth. A structure in the pigeon inner ear, resembling Bast's valve in mammals, is described.
\end{abstract}

Keywords Utriculo-endolymphatic valve - Bast's valve · Pigeon - Avian inner ear · 3D-reconstruction .

Light microscopy

\section{Introduction}

The utriculo-endolymphatic valve at the anteromedial wall of the utricle, was discovered by Bast in 1928 in human fetuses [1]. The utricular duct connects the utricle with the saccular space, close to the entrance of the endolymphatic

\footnotetext{
R. Hofman $(\varangle) \cdot$ J. M. Segenhout $\cdot$ H. P. Wit

Department of Otorhinolaryngology,

University Medical Center Groningen,

P.O. Box 30001, 9700 RB Groningen, The Netherlands

e-mail: r.hofman@kno.umcg.nl

J. M. Segenhout

e-mail: j.m.segenhout@kno.umcg.nl

H. P. Wit

e-mail: h.p.wit@med.umcg.nl
}

duct. Bast [2] suggested that the function of the valve was closing of the utricular end of the utricular duct.

Up to now, the exact function of the valve is still not established. Bast himself proposed rotation of the valve lip at its base, where it is made-up of loose periotic tissue, as the functional mechanism. With rising intra-utricular fluid pressure the valve closes by pressing the lip against the opposing utricular wall [2].

A second theory proposes the opposing utricular wall as the functional part of the valve: bending of the single cell layer of the highly compliant utricular wall opposite the lip is responsible for the opening or closure of the valve [3-5].

In the early decades of the twentieth century, some experimental results indicated a possible function of the valve. Bast [6] reported two cases of ruptured saccules in human ears, resulting in a closed valve and an expanded utricle. Bast and Eyster [7] withdrew endolymph from the cochlear duct of the guinea pig, causing a collapsed saccule and cochlear duct, while the utricle was distended and the valve closed. Konishi [8] found open valves in the guinea pig at various stages of endolymphatic hydrops, after operatively obstructing the endolymphatic duct.

Although there is no conclusive evidence up to now, Bast's valve seems to be capable of protecting the utricle and the semicircular canal system when the evolutionary younger, cochlear part of the system ruptures.

In the evolutionary chain of land living vertebrates, amphibians and reptiles have hearing organs that are small specialized regions of their vestibular systems. In birds, with a cochlear duct, a clear distinction can be made between an inferior and a superior part of the labyrinth. If the function of Bast's valve in mammals is a protective one, it is expected to find a similar structure in birds between the two parts of the labyrinth. 
Retzius [9] made highly detailed drawings of the labyrinth of the pigeon and depicted the connection between the utricle and the saccule as a simple hole in a membrane. No utricular duct, nor a valve-like structure, is visible in Fig. 1.

The drawing of Satoh [10] of a light microscopic slide shows a somewhat more detailed view of the same region in the pigeon. But also in this drawing little evidence for a valve-like structure between utricle and saccule can be found (Fig. 2).

As part of a larger project to reconstruct the entire pigeon's inner ear in three dimensions, we investigated the transition region between utricle and saccule in detail using light microscopy. Our objective was to obtain detailed information on a structure which resembles Bast's valve to some extent. This structure consists of a duct between utricle and saccule, with an overhanging ridge and a slit-like opening on the utricular side of the duct.

Detailed light microscopy results and 3D-reconstructions from the light microscopy slides of the structure and its location are presented.

\section{Materials and methods}

Three healthy pigeons (Columbo Domestica), with a weight of $400-500 \mathrm{~g}$, were used. Animal care and use were approved by the Experimental Animal Committee of Groningen University, protocol No. 2883, in accordance with the principles of the Declaration of Helsinki General anesthesia was induced by intraperitoneal administration of pentobarbital (6\%, overdose, hospital farmacist). After decapitation,

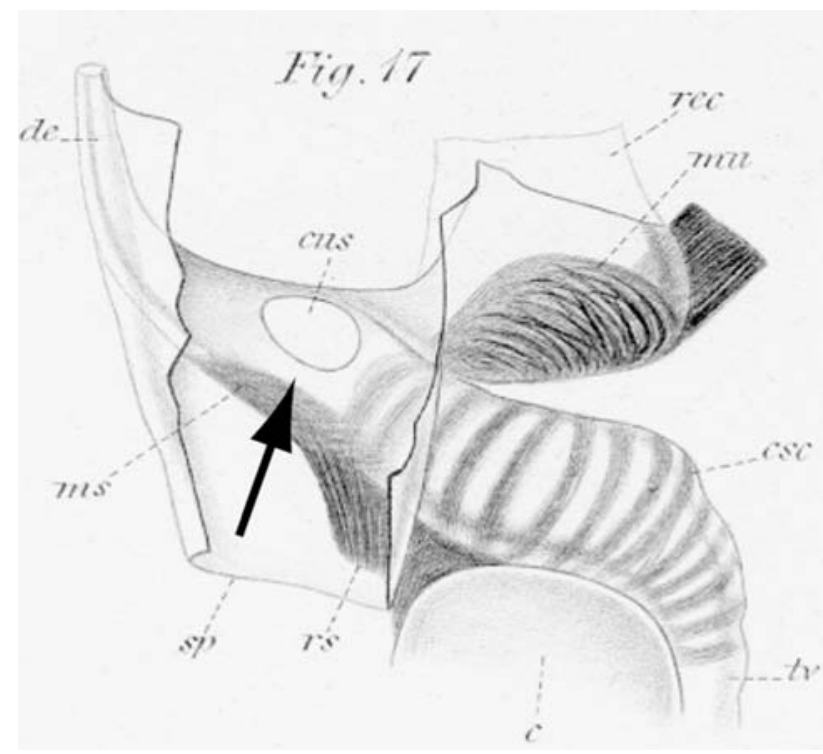

Fig. 1 Drawing of the junction between the utricle and saccule seen from the utricular side by Retzius (1881) (arrow the hole between the utricle and the saccule)

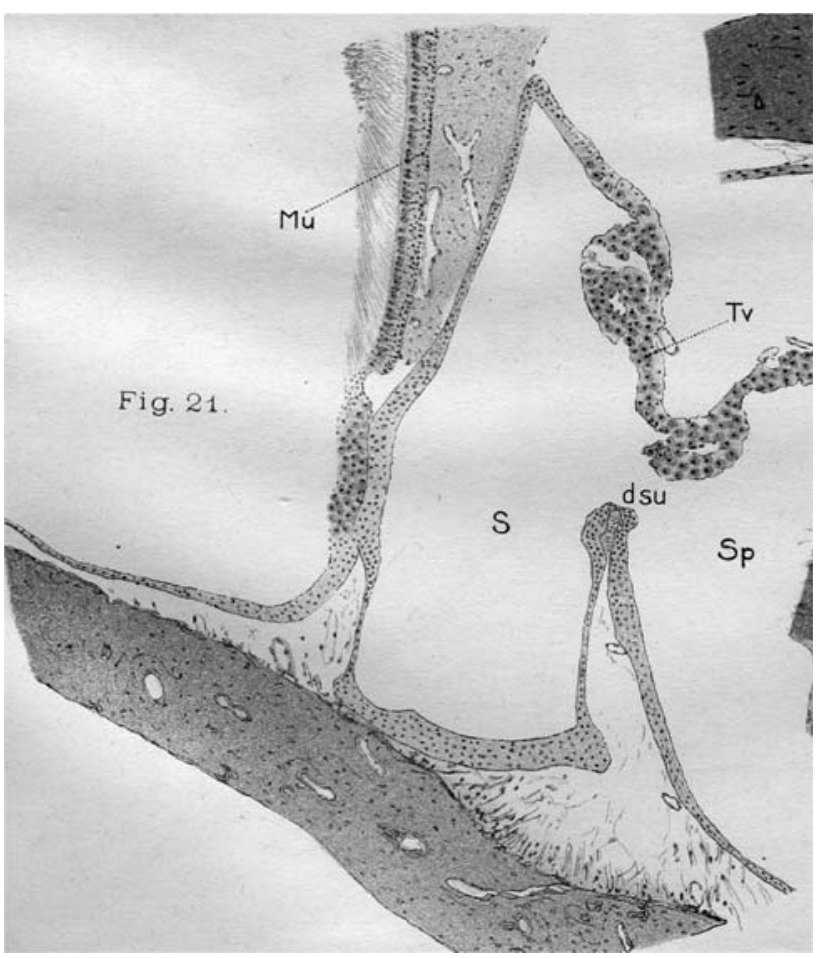

Fig. 2 Drawing of a light microscopical slide of the region between the utricle and saccule in pigeon by Satoh (1917) ( $s$ saccule, $S p$ posterior part of utricle, $T v$ tegmentum vasculosum, $d s u$ utriculo-saccular duct)

all inner ears were fixated in an $8 \%$ neutral buffered formalin solution ( $\mathrm{pH} 7.34)$ for at least $24 \mathrm{~h}$.

Then the specimens were rinsed in aqua-dest. Decalcification in ethylenediaminetetraacetic acid $10 \%$ solution (EDTA; Sigma, ED5SS, pH 7.4) took place at a temperature of $50^{\circ} \mathrm{C}$ in a microwave oven (T/T MEGA microwave histoprocessor, Milestone) in eight sessions of $6 \mathrm{~h}$. After decalcification, the specimens were again rinsed with aquadest and dehydrated in a graded seven-step ethanol series $(30,50,70,90,96,100,100 \%)$.

The specimens were embedded in HPMA (hydroxypropyl methacrylate, Polysciences Inc.) with addition of a catalyst ( $N, N$-dimethlaniline, PEG 400; 15:1, Fluka Chemie AG).

As fiducial markers for 3D-reconstruction five holes (diameter $0.5 \mathrm{~mm}$ ) were drilled in the HPMA-block, perpendicular to the surface. Sections of $4 \mu \mathrm{m}$ were cut and each sixth section was stained with toluidine blue and contrast-stained with basic fuchsine to facilitate reconstruction. Sectioning was not automated (Microm microtome, Heidelberg). A total of 13 sections was used for 3D reconstructions.

The stored 2D images were processed with an IMOD (http://bio3d.colorado.edu/imod) software package for 3D-reconstruction. The input of relevant contours in each 2D-image was manually performed with a writing tablet (Wacom Cintiq 15X). 


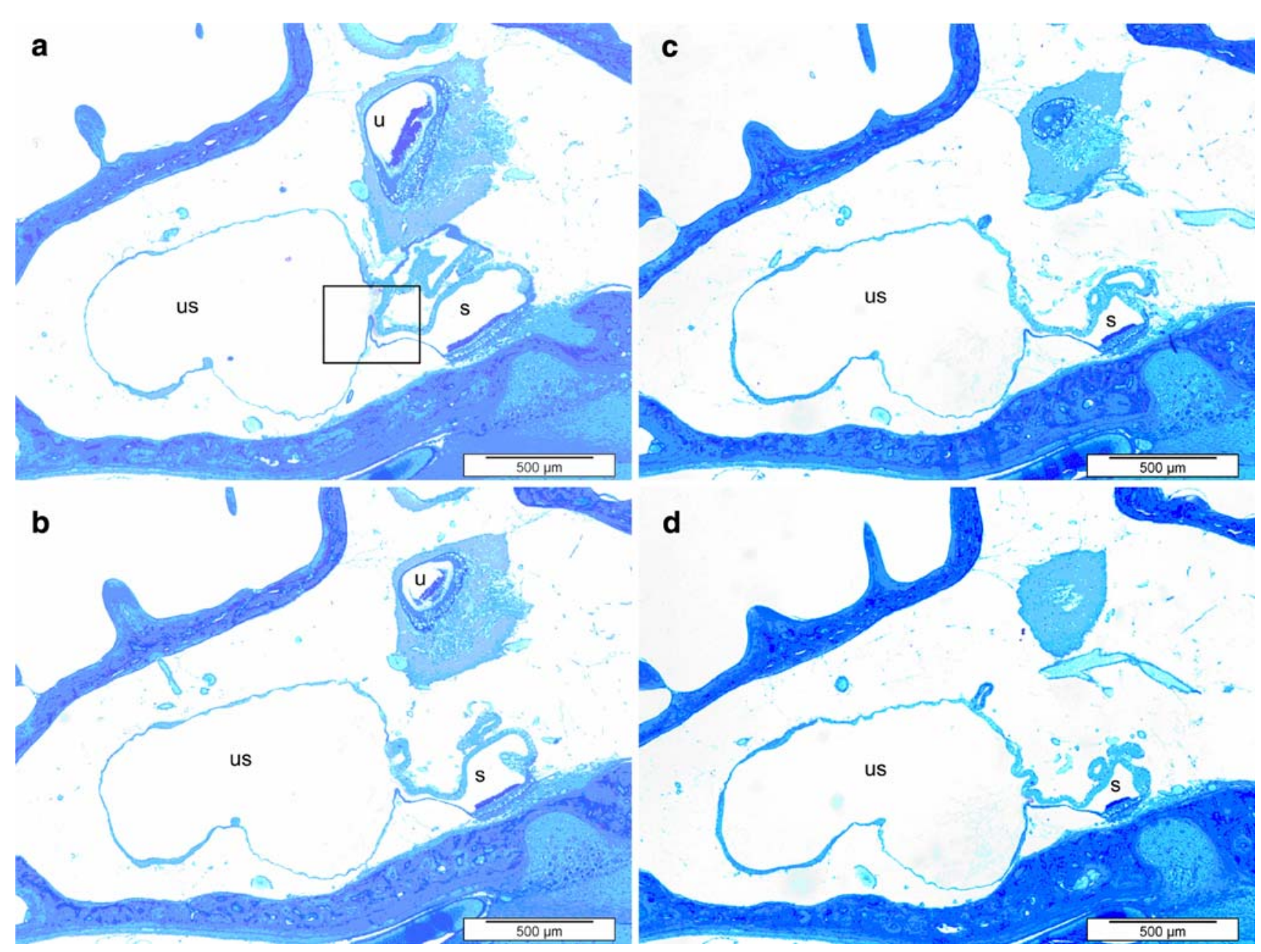

Fig. 3 Subsequent light-microscopy sections of the entrance of the utricular duct ( $s$ saccule, $u s$ utricular space, $u$ utricle). The structures inside the rectangular box are shown in more detail in Fig. 4

Stacking of the LM slides was executed with MIDAS software for manual alignment and adjustment (MIDAS is part of IMOD), using the drilled fiducial markers as references. Corrections to be made were at most a few percent of the 2D-image cross section. If after 3D-reconstruction is larger irregularities were observed, the MIDAS procedure was repeated for the relevant subsequent 2D-slides.

\section{Results}

Figure 3a-d shows subsequent ( $24 \mu \mathrm{m}$ distance) lightmicroscopy images of a duct connecting the utricular and the saccular spaces. The images show the shape of the entrance of the utricular duct at the uticular side. Inaddition, the utricular and saccular spaces and maculas can be seen.

The valve-like structure inside the box in Fig. 3a is shown in more detail in Fig. 4. In this figure connective tissue (dense; non-compliant) in the valve-lip surrounded by a single cell-layer and the opposing single cell-layer wall of cylindrical epithelia (hypodense; compliant), separating the perilymphatic space from the endolymphatic space in this region, can be distinguished. Furthermore, an accumulation of toluidine dyed endolymph at the entrance of the duct can be seen.

Figures 5 and 6 show the slit-shaped opening of the utricular duct at the utricular side. Figure 5 also shows the shape and course of the utricular duct.

Figure 6 shows a raw 3D-reconstruction of the entrance of the utricular duct as seen from inside the utricle.

\section{Discussion}

As far as we know this is the first description of the utricular duct and a utriculo-endolymphatic valve-like structure in the bird. Satoh [10] does indicate a utriculo-saccular duct ( $d s u$ in Fig. 2), and although the figure shows some resemblance with Fig. 3b, the structure appears more like a hole than a duct and no clear valve-like structure is visible. 


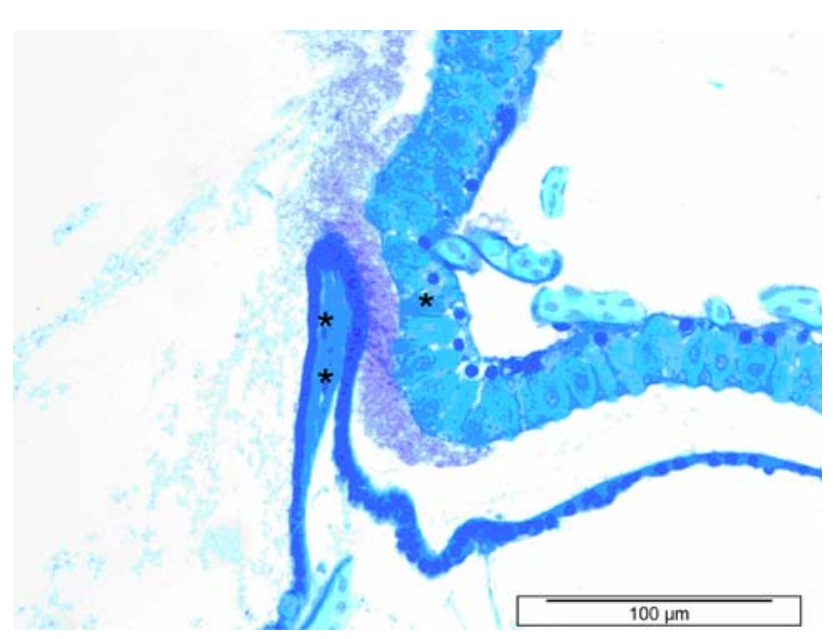

Fig. 4 Detail of Fig. 3a showing a valve-like structure consisting of a ridge overhanging the entrance of the duct (single asterisk compliant cylindrical epithelia tegmentum vasculosum, double asterisks overhanging ridge consisting of rigid non-compliant connective tissue)

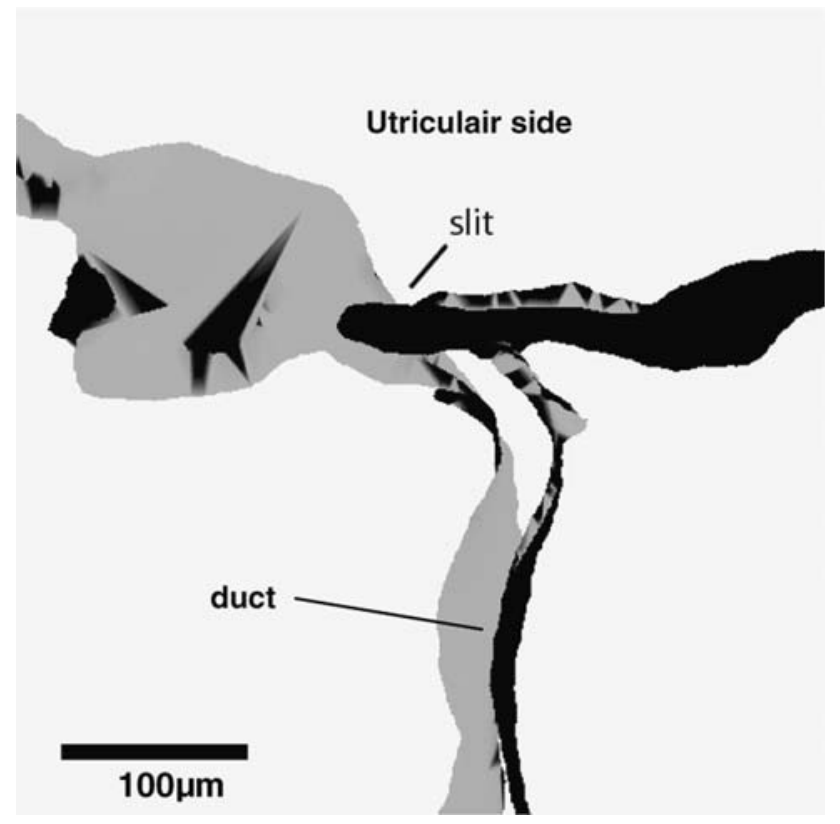

Fig. 5 3D-reconstruction the utricular duct. The duct is drawn open on both sides to give a good impression of the flat cylindrical shape of the duct

The position of the duct is shown in Fig. 7. Because we had only 2D-slides with in-between distances of $24 \mu \mathrm{m}$ available the 3D-reconstructions in Figs. 5 and 6 are not very detailed, but they give a fairly good impression of the shape of the entrance of the utricular duct at the utricular side. The ridge overhanging the slit in Fig. 5 appears as a relatively rigid structure. It is filled with rigid, non-compliant connective tissue, as can be seen in Fig. 4. This rigid structure, in combination with the more compliant celllayer opposite to it, could function as a valve, like it is postulated to do in mammals.

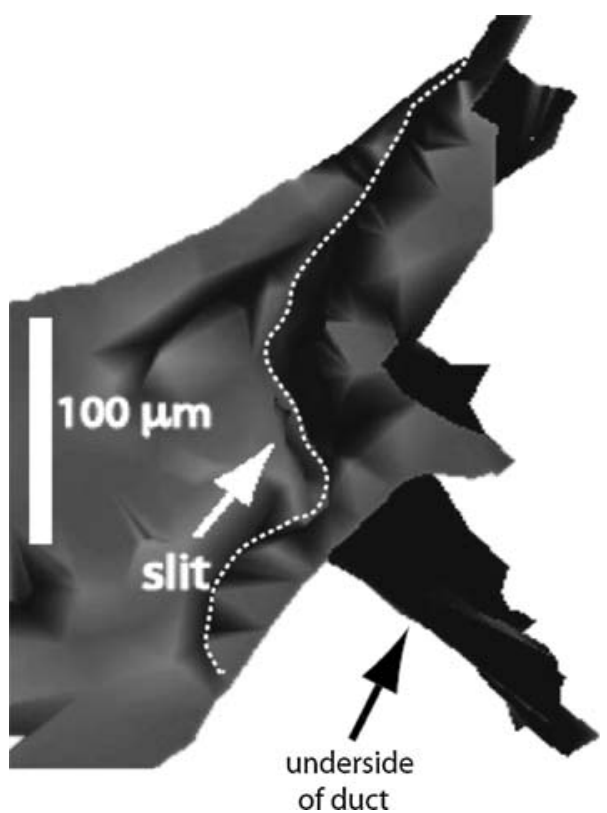

Fig. 6 3D-reconstruction of the entrance (slit-like) of the utricular duct as seen from inside the utricule. The dashed white line follows the edge of the valve-lip overhanging the slit entrance

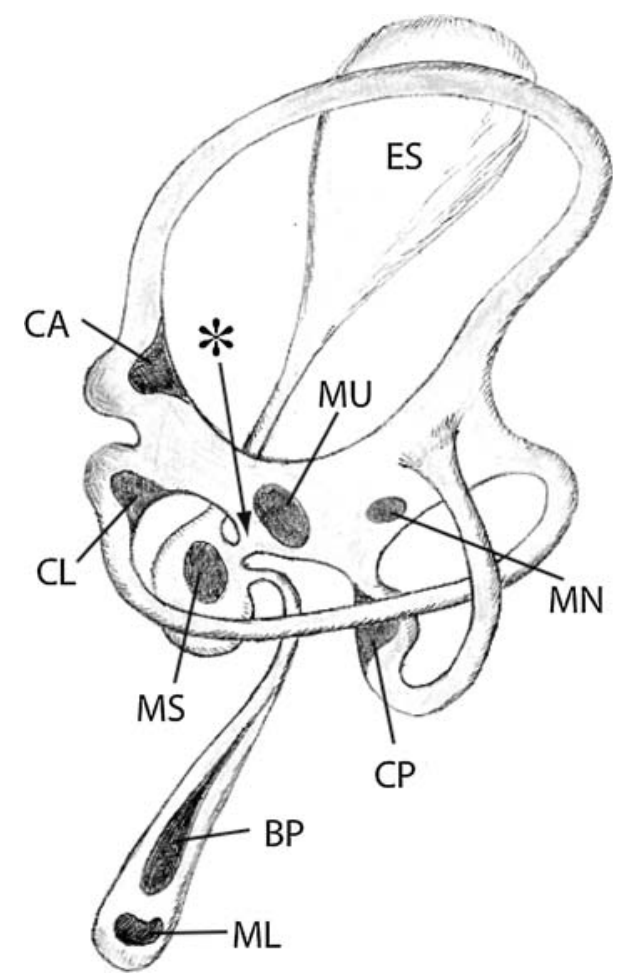

Fig. 7 Schematic drawing by one of the authors (HPW) of the left whole labyrinth of the pigeon. The arrow marked with an asterix points toward the utricular duct and the region of the valve. $B P$ basilar papilla, $C A$ crista in anterior ampulla, $C L$ crista in lateral ampulla, $C P$ crista in posterior ampulla, $E S$ endolymphatic sac, $M L$ macula of the lagena, $M N$ macula neglecta, $M S$ saccular macula, $M U$ utricular macula 


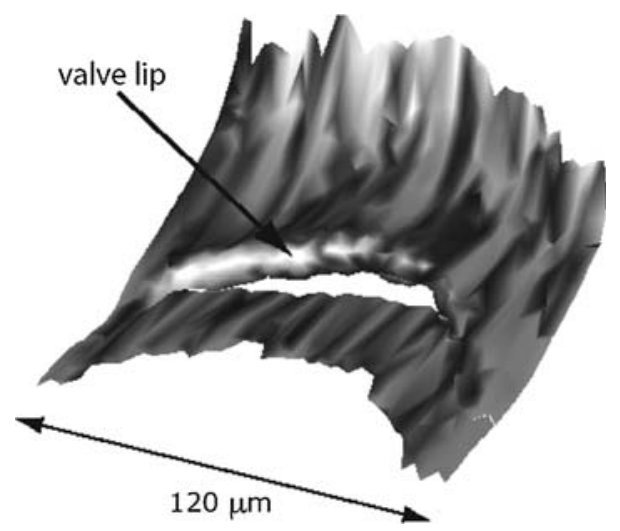

Fig. 8 3D-reconstruction of the entrance (utriculo-endolymphatic duct/Bast's valve) of the utricular duct in guinea pig as seen from inside the utricule (Hofman et al. 2008)

The slit-shaped valve entrance at the urticular side (Fig. 6) resembles this entrance in the guinea pig, as shown in Fig. 8 [5]. Bast [2] also referred to this opening as slitlike in the guinea pig.

Shape and diameter of the utricular duct are different in the guinea pig and the pigeon. In the guinea pig the shape of the duct is that of a flat funnel with a diameter in the order of $10 \mu \mathrm{m}$ at its narrowest passage. In this way, it could prevent rapid flow of endolymph. In the pigeon, the shape of the duct is that of a tube with an elliptical cross section with a largest width of about $200 \mu \mathrm{m}$ along its whole course.

\section{Conclusion}

A structure comparable to the utriculo-endolymphatic (Bast's) valve in mammals can be found in the pigeon. Like in mammals its function is possibly the protection of superior part of the labyrinth against endolymph loss caused by a rupture of the membrane surrounding the inferior part.

Acknowledgments This study was supported by the Hensius Houbolt Foundation and is part of the research program of our department: communication through hearing and speech. The program is incorporated in the Sensory Systems Group of the Groningen Graduate School for Behavioral and Cognitive Neuroscience.

Open Access This article is distributed under the terms of the Creative Commons Attribution Noncommercial License which permits any noncommercial use, distribution, and reproduction in any medium, provided the original author(s) and source are credited.

\section{References}

1. Bast TH (1928) The utriculo-endolymphatic valve. Anat Rec 40:61-65

2. Bast TH (1937) The utriculo-endolymphatic valve and duct and its relation to the endolymphatic and saccular ducts in man and guinea pig. Anat Rec 68:75-93

3. Anson BJ, Wilson JG (1929) The utricular fold in the adult human ear. Anat Rec 43:251-255

4. Schuknecht HF, Belal AA (1975) The utriculo-endolymphatic valve: its functional significance. J Laryngol Otol 89:985-996

5. Hofman R, Segenhout JM, Buytaert JA et al (2008) Morphology and function of Bast's valve: additional insight in its functioning using 3D-reconstruction. Eur Arch Otorhinolaryngol 265:153-157

6. Bast TH (1934) Function of the utriculo-endolymphatic valve. Two cases of ruptured saccules in children. Arch Otolaryngol 19:537-550

7. Bast TH, Eyster JAE (1935) The function of the apical turns of the cochlea and the symptoms of a lesion in this location. Discussion from the point of view of animal experimentation. Trans Am Otol Soc 68:99-112

8. Konishi S (1977) The ductus reunions and utriculo-endolymphatic valve in presence of endolymphatic hydrops in guinea pigs. J Laryngol Otol 91:1033-1045

9. Retzius G (1881) Das Gehörorgan der Vogel. Das Gehörorgan der Wirbelthiere. Central Druckerei Samson \& Wallin, Stockholm

10. Satoh N (1917) Der histologische Bau der Vogelschnecke und ihre Schädigung durch akustische Reize und durch Detonation. Benno Schwabe \& Co., Verlag, Basel 